\title{
Cheek Pouch
}

National Cancer Institute

\section{Source}

National Cancer Institute. Cheek Pouch. NCI Thesaurus. Code C111156.

An evagination of the oral mucosa within the cheek of some mammals, which forms a

pocket. 